\title{
1. Introduction: the roles and - significance of choice experiments in developing country contexts
}

\section{Jeff Bennett and Ekin Birol}

\section{LOOKING BACK}

One of the growth areas in the formulation of policy advice in developed countries over the past decade has been the integration of environmental non-market values into the decision-making process. This has particularly been the case in European Union (EU) countries where EU Directives must be supported by cost-benefit assessments inclusive of environmental impacts. In the UK, the Department of Environment, Food and Rural Affairs (DEFRA) sanctions the use of specific non-market valuation techniques. It is also the case in the United States, where many non-market valuation tools were initially developed. For example, environmental damage cases in law must be supported with evidence of the impacts involved in monetary terms consistent with the compensatory principle. The Regulatory Impacts Assessment (RIA) process in Australia - which is mandated at State and Federal government levels for the introduction of new policy - requires full cost-benefit analysis, and so the call for the inclusion of non-market values in that country has grown.

In addition to environmental policy, non-market valuation techniques have gained increased prominence in other public sector spheres including health and transportation. Governments seeking information on the relative preferences of the community for alternative transport infrastructure outcomes or medical facility investments have applied non-market valuation methods to inform the design of efficient and effective policies and programmes.

While non-market valuation techniques have now become widely accepted as tools of public sector decision-making in developed countries, it must also be recalled that certain of them were initiated in the private sector, most notably the choice experiment method. In that context, firms seeking information regarding their customers' preferences for potential new products have used these tools and continue to do so. Indeed, the distinction between private and public sector application has been blurred, given that government agencies have 
used non-market valuation techniques to investigate the implications of public policies on private goods markets.

The inclusion of non-market values has allowed the decision-making process to extend beyond the consideration of financial impacts and so provide the rigour of welfare economic analysis where environmental and social impacts are involved. This includes uses in ex ante planning contexts as well as expost assessments of prior decisions.

This progression from conventional cost-benefit analysis to the 'extended' version of the technique - that is increasingly invoked by the public sector in developed countries with its incorporation of non-market values - has come about for a number of reasons. First, there has been a growth in demand. The non-market effects of policy, and the environmental and other societal impacts especially, have become relatively more important to the citizenry and hence to democratically elected policy makers. In turn, this growth has been predicated on growing levels of income and (associated) knowledge. As more and more elements of consumptive demand have been satisfied, people have looked toward fulfilment of their environmental protection desires. This trend has been accelerated through increasing scarcity of environmental assets and greater awareness of their importance. The inclusion of non-market values thus provides for the recognition of these changes in relative preferences but also maintains the 'rational' decision-making process established by welfare economics consistent with the ascendancy of the economic agencies in policy development.

In the private sector, on the other hand, having the details of demand structures (such as niche markets or optimal prices to charge for new products and services) from studies that use non-market valuation tools provides firms with an advantage in tailoring supply to meet that demand so as to improve profitability.

Progress has also been achieved on the supply side of the valuation story. Along with a better-educated cohort of practitioners, particular conceptual and methodological breakthroughs have added to the capacity of the economics profession to provide non-market value estimates of costs and benefits of proposed policies, programmes or goods and services. For instance, McFadden's (1974) development of the random utility model (RUM) that underpins most of the stated preference techniques for estimating non-market values is a case in point and one that was recognized in 2000 through the award of the Nobel Prize in economics. Increasing computational power through faster computer chip technology has been an important practical adjunct to this conceptual development.

It is useful to contemplate the growth in interest and capacity in non-market valuation as part of the conceptual framework provided by the Environmental Kuznets Curve (EKC). Fundamentally, the EKC plots out the relationship 
between economic growth and environmental protection over time. The observation has been that, as growth is achieved, the environment suffers until a threshold is reached when the trend is reversed. The implication is that economic growth (eventually) provides the impetus and the capacity for environmental improvement.

The EKC remains a contentious concept. Part of the reason for the contention is that there is a consistent danger that the concept leads to the conclusion that environmental protection is an automatic outcome of economic development. The temptation that follows is for developing country policy makers to focus on furthering economic growth confident in the knowledge that environmental degradation will (eventually) cease and improvement will (eventually) prevail.

This conclusion is invalid. Specific action on the part of policy makers is required to reverse the degradation trend. What the EKC concept suggests is that growth is conducive to those actions being taken. Specifically, growth begets greater disposable income which allows people to extend their preferences beyond those associated with the goods and services related to immediate survival to include environmental protection. Growth also generates the income to devote to research and development to provide the technological capacity to satisfy these extended preferences.

As with the environment, the growth process has seen increases in the interest shown by consumers of other public goods and services such as those related to health, transport and safety, as well as private goods and services on matters such as the health and safety impacts of the products they buy. For example, Delgado (2005) remarks that food consumers are able to pay for certain food safety and quality attributes once their incomes exceed USDl0 a day. It is only once the survival requirements of people have been satisfied that these interests in quality and quantity of public and private goods and services emerge and producers as well as policy and other decision makers begin to move toward changing their policies, outputs and methods of production in response.

\section{LOOKING FORWARD}

A particularly important insight provided by the $\mathrm{EKC}$ relates to the development process. The EKC shows the danger of allowing environmental degradation to proceed (along with economic growth) so that key, irreversible thresholds are breached. These may relate to elements such as species extinction or the contamination of sites. Policies can be specifically targeted to avoid these consequences.

Private-sector firms can also move to outputs and production techniques that pre-empt shifts in consumer demand toward healthier, safer, more environmentally sound products. In this way, producers can take the lead and 
avoid some of the negative environmental and social consequences of a conventional growth path.

The advantage enjoyed by developing country policy makers and privatesector producers is that, in many cases, the experience of developed nations offers remedies to avoid the pitfalls they have encountered through their growth phase or to 'short-cut' to a more sustainable growth path. Such experience can take the form of technological solutions such as pollution control equipment or more advanced breeding stock. But it can also take the form of advanced policymaking and demand-forecasting processes and techniques. Non-market valuation techniques, applied in both the private and public sectors, fall into this category. Put simply, the application of these techniques in developing country contexts offers a potential 'short cut' to the development process that can avoid the environmental and other societal irreversibilities of economic growth and speed the progression to the phase of development where both economic growth, social well-being and environmental improvement can be achieved simultaneously.

The goal of this book is to assist in this 'short-cutting' of the development process through the acceleration of improvements in public policy-making and commercial production in developing countries. In particular, the aim is to focus on the capacity of a specific non-market valuation technique, namely the choice experiment method (CEM), to provide robust and relevant information for the decision-making processes where environmental and societal impacts are expected in developing country contexts. This aim is achieved through demonstration. A series of case-study applications is presented which are designed to encourage further use. This encouragement is directed toward existing practitioners seeking confidence to extend their range of application to developing country contexts, as well as prospective practitioners, especially those from developing countries. It is also aimed at policy advisors and makers as well as commercial interests in developing countries. The studies reported in the following chapters show the potential of this technique in a wide range of circumstances. It is argued that these cases represent the tip of a much larger 'iceberg' of public policy issues and private-sector issues that could be informed through the application of choice experiments. As well as developing country public-sector officials, the book provides evidence of the merits of choice experiments to international development assistance agencies, including organizations engaged in developing country research projects.

The same policy roles that have become accepted for non-market value estimation in developed countries are just as or more important in developing countries. The imperative for planning the use of scarce resources and assessing the success or otherwise of existing resource use choices may be argued to be even greater in the developing country context. Given that developing countries are, by and large, lower down the 'learning curve' of policy than their developed country counterparts, the return to an investment in improving policy making 
in developing countries is likely to be greater. This volume aims to facilitate a move along the policy learning curve for developing countries.

\section{CHOICE EXPERIMENTS}

The choice experiment method (CEM), also known as choice modelling (CM), is a stated preference method of non-market valuation, originally developed in the marketing and transport economics literature (see, for example, Louviere and Hensher 1982; Louviere and Woodworth 1983; Louviere 1988; Louviere 1992), but increasingly adopted in other sectors, such as environment, health and agriculture, over the last two decades. The theoretical grounding of this method lies in Lancaster's characteristics theory of value (Lancaster 1966), and its econometric basis in the models of random utility (Thurstone 1927; Manski 1977). CEM is based on the notion that any good, service, policy or programme can be described in terms of its characteristics, or attributes, and the levels that these attributes take (with or without any interventions). Once attributes and their levels are identified, experimental design theory is used to generate different profiles of the good, service, policy or programme in terms of its attributes and levels these attributes take. These profiles are then assembled in choice sets, which are presented to the respondents, who are asked to state their preferred alternative in multiple occasions. Hanley et al. (1998) define the CEM as a highly 'structured method of data generation'.

One of the attributes included in a choice experiment study is monetary, such as the price for a private good or a tax for a public good. The monetary attribute and the random utility framework on which the CEM method is based allow for the estimation of welfare estimates, that is, willingness to pay (WTP) or willingness to accept (WTA) compensation, for changes in the levels of the attributes of the good, service, policy or programme (Hanemann 1984). The CEM can equip decision makers with four types of information that can inform the development of more comprehensive cost-benefit analyses (CBAs). These include:

(i) which attributes are significant determinants of the values that stakeholders (for example, local or national public, consumers of a product or service, farmers, visitors to a recreational site) place on the goods, services, policies or programmes;

(ii) the implied ranking of these attributes amongst the relevant stakeholders;

(iii) the value of changing more than one of the attributes at once; and

(iv) the total economic value of the good, service, policy or the programme to each stakeholder group and the overall population (Bateman et al. 2003). 
The number of applications of the CEM is increasing rapidly, as is evident from the ever-growing numbers of applications of this method (Ben-Akiva and Lerman 1985; Louviere et al. 2000; Bennett and Blamey 2001; Ryan and Gerard 2003; Kanninen 2007; Birol and Koundouri 2008; Guttmann et al. 2009). The popularity of the method is due to three main factors.

First, the CEM has various advantages over other valuation methods, such as the other stated preference method (that is, the contingent valuation method (CVM)). The main advantage of CEM over CVM lies in its ability to measure the value of multiple attributes that make up a good, service, policy or programme, in addition to the total values of these. In addition, the ability of CEM to decompose the value of the good, service, policy or programme into the values of its attributes makes this method more applicable to benefits transfer compared with the CVM (Hanley et al. 1998; Bateman et al. 2003).

The CEM also avoids several of the biases prevalent in CVM. First, the response difficulties in CVM (for example, 'yeah-saying' bias in dichotomous choice contingent valuation studies and the difficulty of stating a value in an open-ended contingent valuation) can be avoided in CEM. Second, strategic bias is also minimized because of the complexity of formulating strategic responses across the multiple choice sets. Third, insensitivity to scale is eliminated because respondents cannot mistake the scale of the good or its attributes as it is integrated into the choice sets. Finally, since levels of the monetary attribute are already predetermined and included in choice experiments, the large discrepancies between WTA and WTP values found in CVM (Kahneman et al. 1990) can be avoided in the CEM.

Second, the CEM also has several advantages over the revealed preference methods (RPM), such as the hedonic pricing method and the travel cost method. Most importantly, unlike RPM, the CEM can elicit the values of goods, services, policies or programmes that have no related or surrogate markets. The CEM can be used to capture the economic benefits or costs generated by non-market goods and services (such as environmental goods and services) as well by new technologies/products that are not yet marketed, or policies/programmes that have not been introduced. Moreover, the CEM also circumvents two major drawbacks of using RPM data, namely, the invariance of attribute levels over time in a single cross-section and the multi-collinearity among the attributes of what is being valued (that is, good, service, programme or policy).

If the attributes and attribute levels of an existing good, service, programme or policy do not vary over time, the value of changes become difficult, if not impossible, to estimate, thereby providing limited predictions of the impact of changing policies or programmes (Louviere et al. 2000). In addition, the new situation (after the change in the quality or the quantity of the existing good or service, or introduction of a new good, service, programme or policy) may be outside the stakeholders' current set of experiences. Thus, simulation of the 
new situation generally involves extrapolation outside the data range used to estimate the model (Adamowicz et al. 1994). CEM, on the other hand, can be designed to cover a wider range of attribute levels in cases where revealed data do not encompass the range of proposed changes in the attributes of a good, service policy or programme. In other words, the CEM can be used to consider an array of policy options and states of the world that are fundamentally different from the existing ones.

The other common problem with RPM, namely, multi-collinearity among multiple attributes, may generate coefficients with the wrong signs or implausible magnitudes, rendering it difficult to separate attribute effects (Greene 2000; Louviere et al. 2000; Freeman 2003; Hensher et al. 2005). Separation of these attributes may be necessary, however, in order to accurately represent benefits and costs in CBA (Adamowicz et al. 1994). The CEM eliminates multi-collinearity among the attributes, because attribute levels in experimental designs are designed as orthogonal (Bateman et al. 2003). The advantages, as well as the disadvantages, of the CEM when compared with CVM and RPM are discussed in greater detail elsewhere (see, for example, Hanley et al. 1998; Louviere et al. 2000; Bennett and Blamey 2001; Bateman et al. 2003).

The third and final reason for the popularity of the CEM is its practicality and relatively lower costs compared with other experimental approaches, such as randomized experiments which are being increasingly employed in the development economics literature. These randomized experiments are generally useful in the evaluation of interventions (such as policies and programmes or introduction of new goods, services or technologies) before and during the programme/intervention. Though these studies provide useful information on the implementation and uptake of these interventions, they are not particularly useful for assessing their long-term viability or sustainability, that is, how participants will be affected in the long run once the intervention ceases (Grosjean and Kontoleon 2009). Further, as with the CVM, most of these randomized experiments provide an assessment of the gross intervention impact rather than the impacts of particular attributes of a given intervention. Therefore they may not be very informative about any additional improvement or follow-up measures that decision makers can adopt to improve the intervention. Finally, evaluation of interventions with randomized experiments may sometimes not be possible, especially when evaluating the impact of very costly interventions, or interventions that are beyond the currently available set of options (for example, a technology not yet developed, a new product not yet in the market, or a policy/institutional change/technology not yet approved by the policy maker). In such cases the CEM would be more suitable for understanding the acceptability or adoptability of new interventions/technologies/policies and for assessing the relative importance of different programme/policy/intervention attributes across and within different stakeholder groups (Grosjean and Kontoleon 2009). 
The CEM has been extensively used in the developed country context to inform various public and private decision-making processes encompassing a wide array of sectors from transportation and health to agriculture and environment (see, for example, Ben-Akiva and Lerman 1985; Louviere et al. 2000; Bennett and Blamey 2001; Ryan and Gerard 2003; Kanninen 2007; Birol and Koundouri 2008; Guttmann et al. 2009). Hence, to date, only a small number of CEM applications have been conducted in developing country contexts. Some notable examples include Scarpa et al. (2003a,b), Othman et al. (2004), Hanson et al. (2005), Naidoo and Adamowicz (2005), Baltussen et al. (2006), Bienabe and Hearne (2006), Hope (2005) and Ehmke et al. (2008), to name a few.

International development agencies are increasingly relying on this method to help inform a variety of economic development policies. Academics and students from developing countries are approaching their developed country counterparts more and more often in order to seek technical support in implementing choice experiments and/or teaching about their use. There is therefore a growing need for a one-stop publication to present the best-practice case studies in implementation of the CEM in developing countries, and highlight the theoretical and practical issues that should be taken into consideration when implementing this method in the developing country context.

The aim of this book is to fill in this research gap by presenting a series of state-of-the-art choice experiment studies implemented in various developing countries in Africa (Ethiopia, Kenya and Uganda), Asia (Cambodia, China, India, Pakistan, Philippines, Sri Lanka and Vietnam) and Latin American and the Caribbean (Chile and Tobago). In each chapter, developed country choice experiment practitioners are teamed up with colleagues from developing countries to present the advances in the CEM theory and practice, and to highlight specific theoretical, methodological and practical issues that should be taken into consideration when implementing choice experiments in developing countries. The case studies presented in this book focus on a variety of environmental and agricultural issues, underlining the versatility of this method in valuing a wide array of interventions (for example, policies, public and private services, new technologies) and emphasizing the usefulness of the CEM in informing efficient, effective and equitable policies for sustainable economic development.

\section{WHAT FOLLOWS}

The choice experiment case studies presented in the following chapters are grouped into five sections, though there are overlaps across the sections due to the nature of this method which allows for the investigation of various attributes/aspects of a good, policy or intervention, at the same time. 
Section 1: Using choice experiments to investigate environmental conservation and economic development trade-offs

In Section 1, four case studies on environmental conservation and economic development trade-offs are presented. Chapter 2 by Brouwer, Haider, Gunaratne and Beardmore reports the results of a CE conducted in Sri Lanka to investigate the local public's preferences regarding conservation of elephants and compensation for the damages that may be caused by their conservation. In Chapter 3, Do and Bennett investigate farming and non-farming respondents' preferences between wetland eco-system conservation and agricultural employment in Viet Nam. Chapter 4 is also on wetland conservation, this time the country of focus is Ethiopia. In that chapter Selassie and Kountouris study the local fishers' preferences between fish stock, fishing permit prices and the conservation of Lake Awassa wetland, an eco-system recognized for the biodiversity riches it supports. The final chapter in this sub-section is by Beharry and Scarpa, who estimate the local residents', and national and international visitors', preferences between coastal water and beach quality (among several environmental attributes) and coastline development in the Caribbean island of Tobago. In each one of these chapters, the authors make policy suggestions as to how to reconcile environmental conservation aims, whether they involve conservation of a specific species or a whole eco-system, with those pertaining to economic development, such as the improvement of local livelihoods or the development of infrastructure.

Section 2: Using choice experiments to investigate environmental conservation and economic development trade-offs: The case of China's Sloping Land Conversion Programme

As with Section 1, Section 2 also investigates the environment and development trade-offs, this time with specific focus on the evaluation of one of the world's most well-resourced environmental conservation programmes, namely, China's Sloping Land Conversion Programme (SLCP). In Chapter 6, Wang, Bennett, Xie and Zhang estimate the urban public's valuation of this programme, specifically their preferences regarding the continuation of the programme and the important aspects thereof. Whereas in the following chapter, Grosjean, Kontoleon and Zhang focus on the rural public's preferences regarding the continuation of the same programme and the aspects which they consider should be promoted in the next phase. This subsection therefore sheds light on to the non-use (Chapter 6) and use values (Chapter 7) generated by the SLCP. Section 2 therefore provides information regarding the design of the next phase of the programme, in terms of which components of the programme to invest in and how much. This information could aid decision makers in maximizing the welfare of the stakeholders involved. 
Section 3: Using choice experiments to estimate developing countries'valuation of unique eco-systems

Section 3 presents two choice experiments which estimate developing country peoples' valuations of unique eco-systems (captured in terms of their WTP). In Chapter 8, Dehlavi, Groom, Khan and Shahab study Karachi residents' valuation of Pakistan's Indus Ecoregion, one of the world's most important ecoregions, harbouring numerous terrestrial and aquatic ecosystems and associated biodiversity resources. In Chapter 9, Villalobos and Huenchuleo estimate the Chilean public's WTP for the conservation of their country's unique Ruil forests and the flora and fauna diversity therein. Although, as discussed above, it is often argued that environmental conservation is a luxury good that can be afforded only by developed nations, the significant and positive WTP values presented in these two chapters are remarkable. These results reveal that the conservation of unique ecosystems and biodiversity riches indeed contributes to the welfare of people in developing country nations. The positive benefits generated by the conservation of these eco-systems should be weighed against the costs of their conservation to provide evidence regarding optimal conservation programmes and policies.

Section 4: Using choice experiments to inform effective and efficient provision of public and private goods and services

Section 4 presents three studies on the use of the choice experiment method to inform effective and efficient provision of public and private goods and services. In Chapter 10, Das, Birol and Bhattacharya apply a choice experiment in two municipalities in West Bengal, India, to investigate residents' preferences for various solid waste management service attributes and to estimate their WTP in terms of higher municipality taxes to receive better services. In the following chapter, Mekonnen, Yesuf, Carlsson and Köhlin study Ethiopian farmers' preferences for local public goods (health care centre or water spring) and private goods (seed and fertilizer). In Chapter 12, Ratanak and Yabe present the results of a choice experiment study they undertook in Cambodia to investigate domestic and international tourists' demands for a private good, namely tour packages, which include environmental and cultural aspects. The results of these studies have important implications as to how best to 'package' and allocate the public and private goods and services, in the face of pressing resource constraints, as faced by developing country decision makers.

Section 5: Using choice experiments to inform the agricultural sector and food industry 
The final section presents four case studies which apply the CEM in the agricultural sector, the largest sector in economies of most the developing countries. The first two chapters, namely, Chapter 13 by Yorobe, Birol and Smale and Chapter 14 by Ruto and Scarpa, investigate agricultural production issues. In Chapter 13, Yorobe, Birol and Smale estimate farmer demand for maize seed technology and associated inputs in the Philippines, shedding light on the acceptability of a new technology, namely genetically engineered maize seed, and the associated inputs that are hypothesized to promote the adoption of this technology. In Chapter 14, Ruto and Scarpa study Kenyan livestock traders' and producers' preferences for various cattle traits. The results of these two chapters convey important messages to the private suppliers of these goods, such as the seed suppliers and livestock breeders, as well as to the public sector, most notably the agricultural extension services, which aim to increase the productivity of the agricultural sector on which the majority of developing country livelihoods depend. In Chapter 15 by Roy, Birol, Deffner and Karandikar and Chapter 16 by Kikulwe, Birol, Wesseler and Falk-Zepeda, consumers' preferences for various food attributes are investigated. In Chapter 15, the authors estimate Indian consumers' demands for food safety and quality, and find that as in their developed country counterparts, consumers in this rapidly growing developing country demand safer and higher quality food. These results have implications in terms of securing higher incomes for those farmers who already produce higher quality and safe food. In the final case study presented in this section, and also in the book, Kikulwe et al. investigate Ugandan consumers' acceptance of a genetically engineered staple food, namely, bananas. The results of this study reveal that consumers of banana, most of whom are also producers of banana, favour this technology which presents consumption and production benefits. These results may shed some light on to the current controversial debate over the introduction of genetically engineered foodstuffs in Africa.

In the final chapter, chapter 17, Birol and Bennett conclude the book by discussing the best practices in the design, implementation and analysis of choice experiments in the developing country context. This last chapter aims to serve as a manual of choice experiment applications in developing countries.

\section{REFERENCES}

Adamowicz, V., J. Louviere and M. Williams (1994), 'Combining stated and revealed preference methods for valuing environmental amenities', Journal of Environmental Economics and Management, 26, 271-92.

Baltussen, R., E. Stolk, D. Chisholm and M. Aikins (2006), 'Towards a multi-criteria approach for priority setting: An application to Ghana', Health Economics, 1 (7), 689-96.

Bateman, I.J., R.T. Carson, B. Day, W.M. Hanemann, N. Hanley, T. Hett, M. Jones-Lee, 
G. Loomes, S. Mourato, E. Ozdemiroglu, D.W. Pearce, R. Sugden and S. Swanson (2003), Guidelines for the Use of Stated Preference Techniques for the Valuation of Preferences for Non-market Goods, Cheltenham, UK and Northampton, MA, USA: Edward Elgar.

Ben-Akiva, M. and S. Lerman (1985), Discrete Choice Analysis: Theory and Application to Travel Demand, Cambridge, MA: MIT Press.

Bennett, J.J. and R.K. Blamey (2001), The Choice of Modelling Approach to Environmental Valuation, Cheltenham, UK and Northampton, MA, USA: Edward Elgar.

Bienabe, E. and R.R. Hearne (2006), 'Public preferences for biodiversity conservation and scenic beauty within a framework of environmental services payments', Forest Policy and Economics, 9, 335-48.

Birol, E. and P. Koundouri (eds) with a foreword by W.L. Adamowicz (2008), Choice Experiments Informing Environmental Policy: A European Perspective, Wally Oates and Henk Folmer's 'New Horizons in Environmental Economics' Series, Cheltenham, UK and Northampton, MA, USA: Edward Elgar.

Delgado, C. (2005), 'Update on the livestock revolution of Asia: Implications for markets', paper presented at the 'Livestock Market Opportunities', at ILRI, Nairobi, 22 August 2005.

Ehmke, M.D., J.L. Lusk and W. Tyner (2008), 'Measuring the relative importance of preferences for country of origin in China, France, Niger and the United States', Agricultural Economics, 38, 277-86.

Freeman, M.A. (2003), The Measurement of Environmental and Resource Values: Theory and Methods (second ed.), Washington, DC: Resources for the Future.

Greene, W.H. (2000), Econometric Analysis (fifth ed.), New Jersey: Prentice Hall International.

Grosjean, P. and A. Kontoleon (2009), 'How sustainable are sustainable development programmes?', World Development, 37 (1), 268-85.

Guttmann, R., R. Castle and D.G. Fiebig (2009), 'Use of Discrete Choice Experiments in Health Economics', CHERE Working Paper, 2009/2, University of Technology Sydney, Australia.

Hanemann, W.M. (1984), 'Welfare evaluations in contingent valuation experiments with Discrete Responses', American Journal of Agricultural Economics, 66, 332-41.

Hanley, N., R.E. Wright and W.L. Adamowicz (1998), 'Using choice experiments to value the environment', Environmental and Resource Economics, 11 (3-4), 413-28.

Hanson, K., B. McPake, P. Nakamba and L. Archard (2005), 'Preferences for hospital quality in Zambia: Results from a discrete choice experiment', Health Economics, $14(7), 687-701$.

Hensher, D., J. Rose and W. Greene (2005), Applied Choice Analysis: A Primer, Cambridge: Cambridge University Press.

Hope, R.A. (2005), 'Evaluating water policy scenarios against the priorities of the rural poor', World Development, 34 (1), 167-79.

Kahneman, D., J. Knetsch and R. Thaler (1990), 'Experimental tests of the endowment effect and the Coase theorem', Journal of Political Economy, 98 (6), 1325-48.

Kanninen, B.J. (ed.) (2007), Valuing Environmental Amenities Using Stated Choice Studies: A Common Sense Approach to Theory and Practice Series: The Economics of Non-Markets Goods and Resources, vol. 8, Dordrecht: Springer.

Lancaster, K. (1966), 'A new approach to consumer theory', Journal of Political Economics, 74, 217-31.

Louviere, J.J. (1988), Analyzing Decision Making: Metric Conjoint Analysis, Newbury Park, CA: Sage Publications, Inc. 
Louviere, J.J. (1992), 'Experimental choice analysis: Introduction and overview', Journal of Business Research, 24, 89-96.

Louviere, J.J. and D.A. Hensher (1982), 'On the design and analysis of simulated choice or allocation experiments in travel choice modelling', Transportation Research Record, 890, 11-17.

Louviere, J.J. and G. Woodworth (1983), 'Design and analysis of stimulated consumer choice experiments or allocation experiments: An approach based on aggregate data', Journal of Marketing Research, 20, 350-67.

Louviere, J.J., D.A. Hensher, J.D. Swait and W.L. Adamowicz (2000), Stated Choice Methods: Analysis and Applications, Cambridge: Cambridge University Press.

McFadden, D. (1974), 'Conditional Logit Analysis of Qualitative Choice Behaviour', in P. Zarembka (ed.), Frontiers in Econometrics, New York: Academic Press, pages $105-142$.

Manski, J. (1977), 'The structure of random utility models', Theory and Decision, 8, 229-54.

Naidoo, R. and W.L. Adamowicz (2005), 'Biodiversity and nature-based tourism at forest reserves in Uganda', Environment and Development Economics, 10 (2), 159-78.

Othman, J., J. Bennett and R. Blamey (2004), 'Environmental values and resource management options: a choice modelling experience in Malaysia', Environment and Development Economics, 9, 803-24.

Ryan, M. and K. Gerard (2003), 'Using discrete choice experiments to value health care programmes: current practice and future research reflections', Applied Health Economics and Health Policy, 2 (1), 55-64.

Scarpa, R., A. Drucker, S. Anderson, N. Ferraes-Ehuan, V. Gomez, C.R. Risopatron and O. Rubio-Leonel (2003a), 'Valuing animal genetic resources in peasant economies: The case of the Box Keken Creole pig in Yucatan', Ecological Economics, 45 (3), $427-43$.

Scarpa, R., E.S.K. Ruto, P. Kristjanson, M. Radeny, A.G. Drucker and J.E.O. Rege (2003b), 'Valuing indigenous cattle breeds in Kenya: An empirical comparison of stated and revealed preference value estimates', Ecological Economics, 45 (3), 409-26.

Thurstone, L. (1927), 'A law of comparative judgement', Psychological Review, 4, 273-86. 
Jeff Bennett and Ekin Birol - 9781781000649 Downloaded from PubFactory at 04/26/2023 12:50:22AM via free access 